\title{
The AK06 kimberlite, Botswana: use of a metallurgical parameter to enhance geological definition in a kimberlite
}

\author{
J. Stiefenhofer ${ }^{1}$; A. Opperman ${ }^{1,2}$ \\ ${ }^{1}$ De Beers Group Services (Pty) LTD., Mineral Resource Management, P.O. Box 82851, Southdale, \\ 2135, SOUTH AFRICA.( johann.stiefenhofer@debeersgroup.com / Fax: +27113747051 / Phone: \\ $+27113747861)$ \\ ${ }^{2}$ Golder Associates Africa (Pty) Ltd. P.O. Box 6001, Halfway House, 1685, SOUTH AFRICA \\ (aopperman@golder.co.za / Fax: +27113150317 / Phone: +27112544873)
}

\begin{abstract}
Introduction
The construction of geological models of kimberlites during an evaluation project suffers due to a lack of outcrop. Geological information is typically obtained through the use of drill hole data, but confident geological models are only possible once considerable delineation drilling has taken place. A case study is presented showing how the inclusion of a metallurgical parameter can be used to 1) enhance geological definition in a kimberlite, 2) corroborate and support the identification of geological units, and 3), contribute towards understanding the volcanology at the time of emplacement.
\end{abstract}

\section{Geology}

The Cretaceous-aged AK06 kimberlite is located in the Orapa kimberlite cluster of north-central Botswana, some $25 \mathrm{~km}$ south of Orapa Mine. The resource forms part of a joint venture agreement between De Beers, African Diamonds Plc and Wati Ventures. Figure 1 shows the north-south oriented, tri-lobate kimberlite complex with a near-surface expression of 4.4 ha (1012 mamsl).

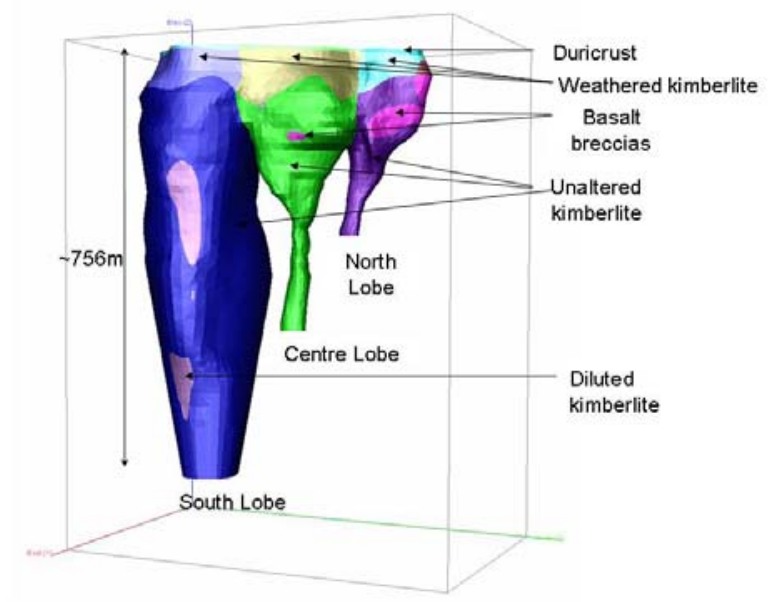

Figure 1: Geological model of the three lobes in the AK06 kimberlite complex. The vertical dimension is $\pm 756 \mathrm{~m}$. Image from Opperman (2007).
Geological investigations have shown each lobe of the kimberlite to represent a distinct kimberlite pipe (Stiefenhofer, 2007a and references therein). The infill is interpreted as volcaniclastic kimberlite. The North and Centre lobes are broadly similar, but completely different from the South Lobe with respect to pipe morphology, infill, petrography, geochemistry and geometallurgical parameters. Chinn et al. (this volume) investigated the diamond populations from each lobe.

Each pipe is capped by duricrust (12m), followed by weathered kimberlite $(30-70 \mathrm{~m})$, before unaltered kimberlite is intersected. Zones of basalt breccia occur within each pipe. The in-fill of the North and Centre lobes resemble typical volcaniclastic kimberlite, but exhibits textural heterogeneity on a macroscopic and microscopic scale. Pyroclasts are evident in places, but elsewhere the kimberlite is considerably more homogeneous in appearance. The South lobe kimberlite in contrast is harder, darker, denser, and exhibits preferential lithic clast orientation and olivine-rich zones in places. The South lobe kimberlite is also less diluted by crustal material. The initial geochemical investigation (see Figure 2 below) was performed using largely unaltered samples, but subsequent sampling of the weathered zones revealed similar results following multivariate

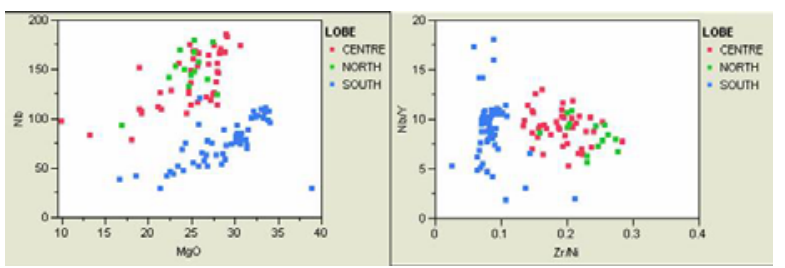

Figure 2: Geochemical distinction between the North/ Centre and South lobes.

statistical analysis. The South lobe is dominated by one kimberlite variety containing fresh groundmass components, including monticellite. Sub-units could be distinguished within each pipe using standard petrographic and geochemical techniques. 
Discriminating petrographic features included crustal xenolith abundance, crustal xenolith type, and groundmass spinel abundance.

\section{Sampling methodology}

Twenty-five large diameter (23-inch) evaluation drill (LDD) holes were sunk vertically into AK06. Samples were collected in $12 \mathrm{~m}$ vertical lifts. Each was preceded by a vertical diamond core pilot hole for geological control, in addition to other angled delineation holes. Continuous down hole data in the form of percentage dense media separator (\%DMS) yield, as well as chip density readings were produced from the LDD holes. The \% DMS yield represents the ratio of the mass of wet concentrate/mass of wet head-feed to the sampling plant for the purpose of this exercise and is a relative value.

\section{Geostatistical analysis of \%DMS yield}

The \%DMS yield data exhibited spatial structure within the kimberlite lobes which allowed the construction of variograms for the major kimberlite lithologies (Figure 3). This in turn allowed the generation of local block estimates $(25 \times 25 \times 12 m)$ of \%DMS yield using ordinary kriging with hard boundaries (Figure 4) (Stiefenhofer, 2007b). The South lobe in particular revealed a wide range of \%DMS yield values. Very high \%DMS yield values in the principal geological unit presented a challenge to the recovery of diamonds. It was therefore essential for mine planning purposes that zones of high \%DMS yield were accurately defined and quantified. Indicator kriging was applied to the South lobe data set to obtain the probability of intersection \%DMS yields above a particular cut-off.

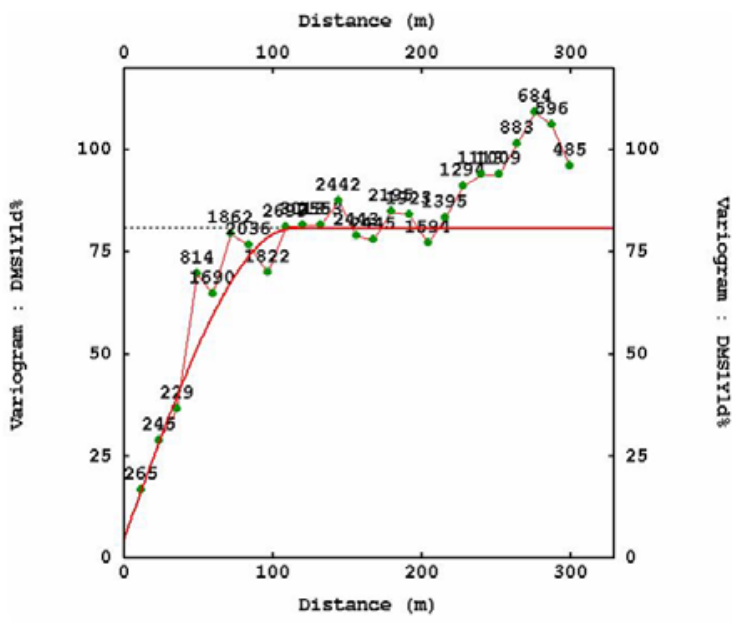

Figure 3: Modeled single-structure spherical variogram of \%DMS yield for the major kimberlite unit in the South Lobe, used to produce some of the estimates shown in Figure 4. Lag=12m, range $=112 \mathrm{~m}$.

Kriging methods however produce a "best" (minimum error variance) linear estimate. The results do not reflect the true histogram and inherent variance or covariance (i.e. variography) that may occur within the dataset (e.g. Journel, 1974; Goovaerts, 1997). A conditional simulation using the Turning Bands method (Matheron, 1973) was generated for the main kimberlite unit in the South lobe to quantify the variance in \%DMS yield per bench and obtain the full distribution of potential uncertainty.

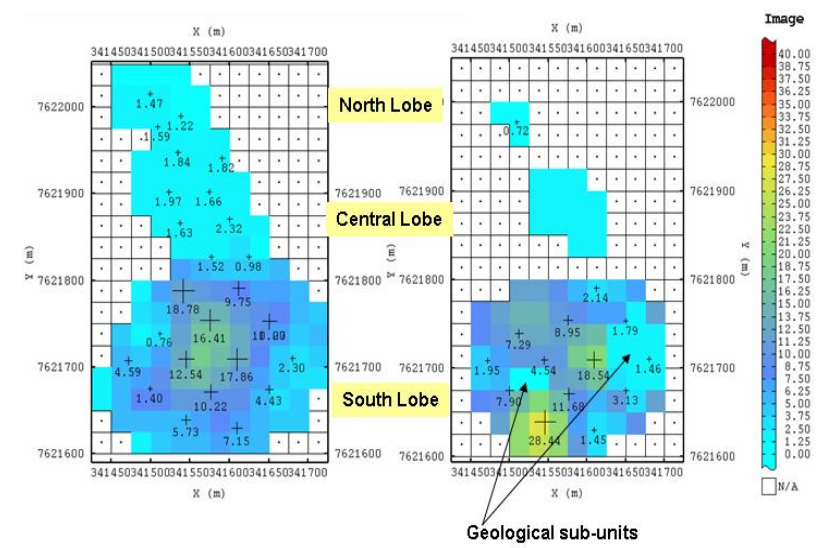

Figure 4: Plan view showing ordinary kriged \%DMS yield estimates of the three lobes on Benches 10 (108m, left) and 22 (252m, right). Numbers and symbol sizes within the kimberlite reflect sample data. The boundary between the South and Centre lobes is clearly visible due to the large difference in \%DMS yield.

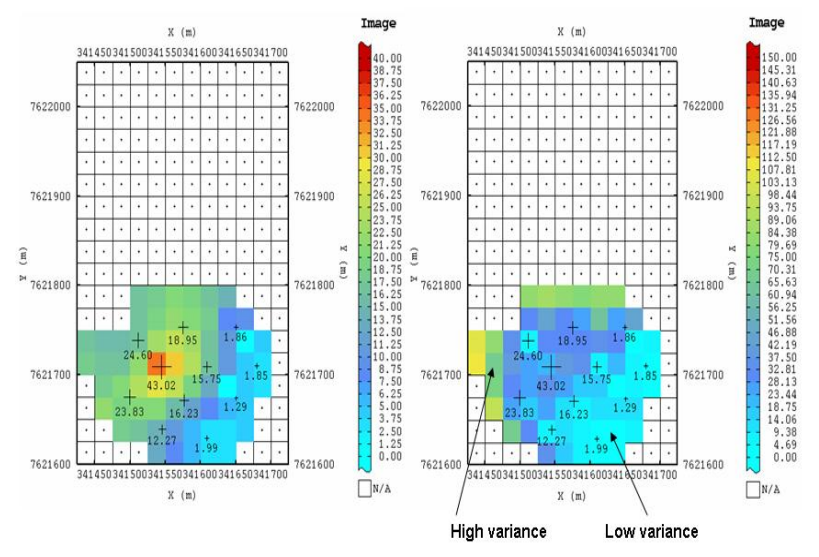

Figure 5: The left-hand image represents the mean \%DMS yield value per node of 100 simulations on Bench 30 (348m) and the right hand image the corresponding variance from these simulations. The minor kimberlite units were not included in the simulations.

\section{Discussion}

Sparks and Field (pers. comm., 2007) reported the presence of sintering textures and interpreted the South lobe infill as pyroclastic kimberlite. This is in agreement with our own observations from core logging and petrographic studies (Stiefenhofer, 2007a). This interpretation is critical in understanding the distribution of \%DMS yield values in the South lobe.

A complex interplay of primary and secondary factors were responsible for the variations in \%DMS yield observed in the AK06 pipe complex and in particular the South Lobe. 
o \%DMS yield is lower for those units exhibiting elevated crustal dilution, e.g. the basalt-rich breccias.

o Primary geological sub-units which formed as a result of volcanic processes may exhibit distinct \%DMS levels (Figures 6 and 7).

o Variable levels of sintering within the main pyroclastic kimberlite of the South lobe would have resulted in variable primary porosity in the kimberlite (Sparks and Field, pers. comm., 2007). It is proposed that areas that suffered the highest levels of sintering have escaped severe fluid flow and alteration, thereby preserving the high primary \%DMS yield. Less sintered, more porous areas exhibited correspondingly higher alteration and therefore lower \%DMS yield.

o More weathered kimberlite exhibits lower \%DMS yield. This applies to weathering as well as postemplacement hydrothermal alteration (e.g. Stripp et al., 2006). The perimeter of the kimberlite may be more altered than the interior on a local scale and may correlate with lower \%DMS yield values.
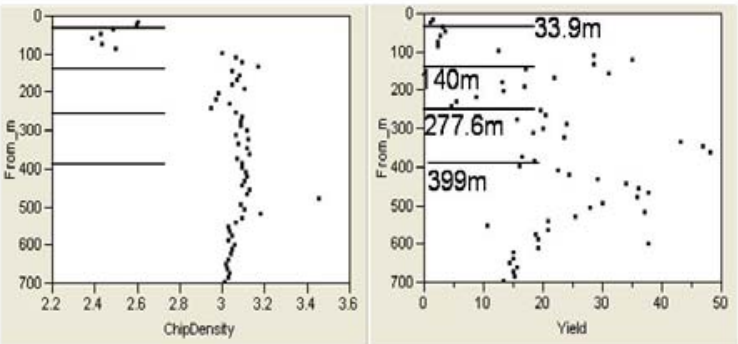

Figure 6: Correlation between logged geology from core hole PLT021 vs. the chip density and \%DMS yield sample data from LDD026 in the South Lobe. Sampling interval is $12 \mathrm{~m}$. Basalt is present up to $33.9 \mathrm{~m}$, but the remainder of the sampling occurred within one major geological unit. Note the gradual, but systematic changes in \%DMS yield. It is suggested that these cyclic changes may be of a primary origin and a reflection of volcanic processes.
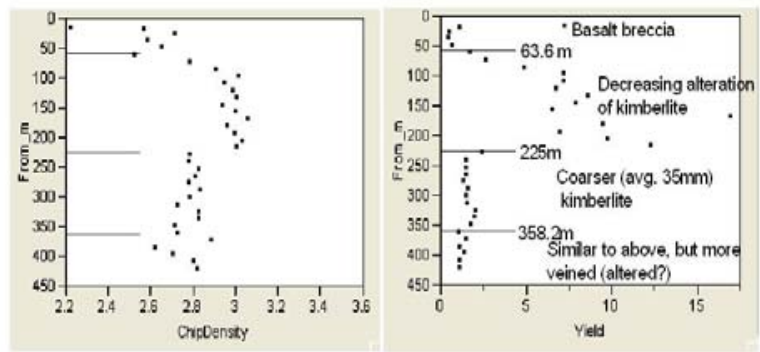

Figure 7: Correlation between logged geology from core hole PLT016 vs. the chip density and \%DMS yield sample data from LDD028 in the South Lobe. Sampling interval is $12 \mathrm{~m}$. Note the change in density where the coarse sub-unit commences.

Assuming that the pyroclastic interpretation is correct, the local \%DMS yield estimates can be used to identify the level of intensity of the sintering process in the South lobe pyroclastic kimberlite. The highest \%DMS yield in the South lobe pyroclastic kimberlite occurs slightly north-west of centre as a single coherent area up to Bench 16 (180m), e.g. Figure 4 (left), whereafter multiple zones of high yield become evident (Figure 4, right) up to Bench 30 (348m), before coalescing into a single zone again. The overall \%DMS yield increases with depth. Geological core logs and geostatistical estimates have shown that continuity is more pronounced in the vertical than in the horizontal direction. It is proposed that the areas of highest \%DMS yield may represent the zone immediately adjacent to the vent or conduit.

\section{Conclusion}

It has been demonstrated that clear geological distinctions between the kimberlite lobes in the AK06 pipe complex can be correlated with metallurgical parameters such as \% DMS yield towards the construction of a geo-metallurgical model. Local \%DMS yield block estimates could be used to enhance the internal definition of the kimberlite and complement the geological data. It is however essential that the geology of the kimberlite is understood before attempting to interpret metallurgical parameters. Superficially similar metallurgical data may be caused by different geological processes, e.g. dilution and alteration.

\section{References}

Chinn, I.; Krug, M.; Minnie, W.; Rikhotso, C. (2008). Relationships between diamond populations and geology from the AK06 kimberlite, Botswana. 9th International Kimberlite Conference Extended Abstract.

Goovaerts, P. (1997). Geostatistics for Natural Resources Evaluation. Oxford University Press, Applied Geostatistics Series, 483pp.

Journel, A.G. (1974). Geostatistics for Conditional Simulation of Ore Bodies. Economic Geology, 69, 673-687.

Matheron, M. (1973). The Intrinsic Random Functions and their applications. Advances in Applied Probability , 5, 439-468.

Opperman, A. (2007). Phase 2 Three Dimensional Geological Modeling of the AK6 kimberlite, Botswana. Report no. 8859/9444/1/G, prepared by Golder Associates Africa (Pty) Ltd. for De Beers Group Services, 14pp.

Stiefenhofer, J. (2007a). The geology of the AK06 kimberlite - July 2007. De Beers Group Services Mineral Resource Management, internal report.

Stiefenhofer, J. (2007b). Geostatistical analysis of the percentage DMS yield from the AK06 kimberlite July 2007. De Beers Group Services Mineral Resource Management, internal report.

Stripp, G.R.; Field, M.; Schumacher, J.C.; Sparks, R.S.J.; Cressey, G. (2006). Post emplacement serpentinization and related hydrothermal metamorphism in a kimberlite from Venetia, South Africa. J. metamorphic Geol., 24, 515-534.

\section{Acknowledgements}

De Beers and African Diamonds Plc. are thanked for permission to publish data from the AK06 project. Clement Rikhotso, Maanda Ratshitanga and Mark Krug are thanked for assisting with sampling and data colation. The De Beers MRM team in Cape Town is thanked for assistance in the execution of the geostatistical analysis. 